\title{
Reescritura de materiales: lectura comparada de $A$ veces cubierto por las aguas de Carlos Cociña y El árbol del lenguaje en otoño de Andrés Anwandter*
}

\author{
Rewriting materials: comparative reading of Carlos Cociña's $A$ \\ veces cubierto por las aguas (sometimes covered by the waters) \\ and Andrés Anwandter's El árbol del lenguaje en otoño (the tree \\ of language in autumn)
}

Diego Zamora Estay ${ }^{* *}$

\section{RESUMEN}

El presente artículo desarrolla una lectura comparada de los Palabras clave: poemarios A veces cubierto por las aguas (2003) de Carlos Cociña y El árbol del lenguaje en otoño (1996) de Andrés Anwandter, a través de un corpus crítico que permite señalar los efectos y las relaciones entre la técnica y la poética de estos autores. Las obras de ambos poetas desarrollan, a partir de la experimentación con la materialidad del poema, diversas formas de reescritura que, desde la presente investigación, acortan la distancia entre lo arcaico y lo novedoso para señalarnos que el tiempo del poema está en la lectura como un acto siempre renovado en el ahora.

\section{SUMMARY}

This article develops a comparative reading of the poetry books A veces cubierto por las aguas (2003) (In English: Sometimes covered by the waters) (2003) by Carlos Cociña and El árbol del lenguaje en otoño (In English: The tree of language in autumn) (1996) by Andrés Anwandter, through a critical corpus that enables the identification of the effects and relationships between technique reescritura, poesía chilena, tecnopoesía, Carlos Cociña, Andrés Anwandter. and the poetics of these authors. Based on experimentation with

Keywords: rewriting, Chilean poetry, technopoetry, Carlos Cociña, Andrés Anwandter.

Este artículo forma parte del proyecto Fondecyt 11170009 "Reescribir o el comienzo de la escritura: poéticas del campo cultural chileno-peruano (1943-2014)" a cargo de la profesora Biviana Hernández.

* $\quad$ Egresado de Pedagogía en Lengua Castellana de la Universidad Academia de Humanismo Cristiano. Santiago, Chile. diegoandres.zamora@gmail.com 
Reescritura de materiales: lectura comparada de A veces cubierto por las aguas | Zamora

poetic materiality, the works of both poets develop various forms of rewriting that, from their research, shorten the distance between the archaic and the novel to point out that the time of the poem is in reading it like an act that is always being renewed in the present. 


\section{Introducción: la técnica y la imagen del mundo}

La relación entre poesía y técnica es inseparable, puesto que todo poema requiere de un medio técnico para su producción. Ya sea la palabra oral o una pantalla táctil, siempre hay un soporte que tan solo por su materialidad designa una forma de ser del poema. Sin embargo, es con la aparición de la imagen técnica que esta problemática provoca lo que la artista y académica Lila Pagola (2011) denomina como "una serie de cuestionamientos a categorías estructurantes de la noción canónica de arte" (9). Estos cuestionamientos son los que nos llevan a pensar en mediaciones entre procesos creativos y aparatos tecnológicos y la puesta en tensión de los conceptos de autoría, originalidad o la participación de terceros en la obra.

La siguiente investigación propone pensar los temas que se derivan de esta nueva relación entre el arte y la imagen técnica a través de los poemarios $A$ veces cubierto por las aguas (2003) de Carlos Cociña ${ }^{1}$ y $E l$ árbol del lenguaje en otoño (1996) de Andrés Anwandter, realizando una lectura en relación con los efectos que producen los soportes materiales en la poética de estos escritores. Ambos autores han trabajado desde la experimentación con el libro objeto o los medios virtuales; en estas dos obras en particular, reconocemos una disposición en común: la inscripción del poema en hojas sueltas.

Realizar un ejercicio comparativo entre las obras de estos dos poetas nos parece de una profunda relevancia en torno a cómo se piensan los medios técnicos que funcionan como dispositivos mediadores en la obra poética. En esta línea, la idea de progreso representado por la novedad de las tecnologías se ve truncada cuando se analizan los usos y las posibilidades que tienen estos medios en los poemas que acá analizamos, los que leemos desde el concepto de poéticas tecnológicas que Claudia Kozak define como "particulares formulaciones en las que los distintos lenguajes artísticos asumen explícitamente su inserción en el mundo técnico que les es contemporáneo" (1).

1 Debido al carácter de nuestra investigación, utilizaremos dos versiones del poemario A veces cubierto por las aguas de manera paralela y comparativa, nos referimos a su primera publicación a través de la página web www.poesiacero.cl (2003) y la que publica ediciones Alquimia a través de la antología Almargen de la propia vida (2013). Como detallaremos más adelante, los distintos soportes de estos poemas nos permitirán pensar en lecturas diferentes según su materialidad. 
Desde la segunda mitad del siglo XX, estas poéticas tecnológicas han ido en aumento, con su respectivo campo de investigación. Obras como Tape Mark I (1961) de Nanni Balestrini, IBM (1966) de Omar Gancedo, Le tombeau de Mallarmé (1972) de Erthos Albino de Souza, Un roman inachevé (1994) de Jean-Pierre Balpe, Anipoemas (1997-2003) de Ana María Uribe y Arteroids (2017) de Jim Andrews son parte de una larga lista de trabajos cuyo eje de desarrollo se encuentra precisamente en el medio tecnológico que disponen como soporte mediador de la obra.

En el caso de Chile, la académica Carolina Gainza, utilizando el concepto "literatura digital" sugiere la constitución de "un campo de creación y experimentación donde podemos encontrar trabajos tanto en narrativa como en poesía" ("Literatura chilena... 237) donde se ubican obras como Clickable poem@s (2016) de Luis Correa-Díaz, Poemas digitales (2004) de René Orellana, Feedback (2014) de Martín Gubbins, Poema del Terremoto (2010) de Gregorio Fontén, el proyecto Orquesta de poetas (2011) de Fernando Pérez, Felipe Cussen, Pablo Fante y Federico Eisner, además de Poesía cero (2003) de Carlos Cociña, que forma parte del corpus acá investigado.

Para Claudia Kozak, en el presente estas poéticas tecnológicas constituyen una tradición de vanguardia que tendría su origen en los poema/proceso, pero sobre todo en la concepción de la literatura entendida como máquina "que produce lenguajes" (4). Esta relación de origen permite desplegar un cuestionamiento a la producción de nuevas tecnologías como prueba del progreso, como veremos en Cociña y Andwanter, al dialogar con la tradición literaria y reescribir en nuevos soportes temáticas de la literatura más tradicional.

A pesar del auge que vienen presentando las poéticas tecnológicas, la estrecha presencia de los medios digitales en la escritura nos ha llevado a una relación pocas veces cuestionada, como nos indica Carolina Gainza en:

Preguntarse por las posibilidades creativas de las tecnologías digitales podría parecer una trivialidad en nuestros días. Lo digital se encuentra en el corazón de la producción cultural, dado que actualmente toda producción artística pasa por algún procedimiento vinculado a estas tecnologías ... Sin embargo, la naturalización de los usos de lo digital en los procesos creativos, por el aumento en la 
disponibilidad y experiencia que tenemos en relación al uso, lectura y manipulación de obras construidas en base a procedimientos digitales, no necesariamente implica una correlación con nuestra comprensión del fenómeno en sus efectos, lógicas de funcionamiento, experiencias, estéticas y modos de creación. ("Literatura chilena... 234)

Gainza sugiere una urgencia por pensar en esta relación a partir de "La nueva analogía" (2014) un breve ensayo de Octavio Paz en el cual se sugiere que la pregunta por la técnica y sus implicaciones en el lenguaje poético van acompañados de una pérdida de la imagen del mundo.

Tomando la urgencia de esta reflexión crítica acerca de la relación entre las nuevas tecnologías y sus implicaciones en el lenguaje poético, proponemos leer los textos de Cociña y Anwandter desde un ejercicio comparativo que pone en relevancia la materialidad de sus obras y el desarrollo de una reescritura en la cual, tal como veremos más adelante, se genera una disposición en movimiento, una lectura que avanza y retrocede, generando una relectura constante que rompe con la idea de principio y final de un libro tradicional.

Las hojas sueltas que encontramos tanto en El árbol del lenguaje en otoño como en A veces cubierto..., tensionan la idea de progreso al descartar la linealidad de su lectura, además de encontrar, como veremos con Cociña, una relación estrecha entre un dispositivo tradicional (la carta), con otro más reciente (motor de búsqueda aleatoria) ${ }^{2}$.

Siguiendo el texto de Paz, tales gestos en el trabajo poético alteran la percepción que tiene el lector respecto de los medios tecnológicos; como diría el autor mexicano, la poesía "es siempre una alteración ... una desviación creadora y que produce un orden nuevo y distinto" (121).

Pero así como estas poéticas transforman nuestra relación con la novedad tecnológica, el avance técnico de la era digital produce al-

2 Esta tensión generada hacia la linealidad de la lectura, no es propiamente un gesto de vanguardia, por el contrario, actualmente se desarrolla dentro de una tradición que incluye obras canónicas como Rayuela (1963) de Julio Cortázar o Cent mille miliards de poèmes de Raymond Queneau, pasando por el desarrollo de la performance y las variadas expresiones poéticas que buscan ir más allá de la noción del libro tradicional. Sin embargo, nuestra intención es realizar una lectura de esa tensión desde la relación con los aparatos tecnológicos recientes. 
teraciones en la escritura poética, "la técnica cambia a la poesía y la cambiará más y más” (124) señala Octavio Paz. En nuestra lectura en particular nos interesa demostrar que la producción poética contamina la manera en que comprendemos estas tecnologías, agudizando la crítica y materializando los aparatos. La poesía devuelve las cosas a su naturaleza original, incluyendo al aparato tecnológico más reciente, lo redime de su carácter mágico ${ }^{3}$, cuyos mecanismos resultan incomprensibles a pesar de estar muy presentes en nuestra cotidianeidad.

La lectura de estos poemas a partir de sus soportes materiales, la relación con los formatos tradicionales como gesto de ruptura y la reescritura de autores anteriores a la modernidad, anuncian la posibilidad que nos entrega el lenguaje poético para poner en tensión nuestro presente, desmontando las ideas de la novedad y el progreso propios de nuestra era. Al situar históricamente estos elementos y evidenciar la relación de los nuevos medios tecnológicos con la tradición remota de la literatura, estamos apostando por pensar nuevamente nuestro tiempo, continuando con la tesis de Paz quien expresa: "la pérdida del futuro nos acerca a maneras de ser y de sentir que parecían extintas" (124), estas nuevas maneras se anuncian a través de la poesía.

Desde esta perspectiva, la poesía de Carlos Cociña y Andrés Anwandter desarrollan una reescritura del presente a través de la relación dialógica entre tradición y novedad.

Cociña, cuya obra ha cobrado mayor vigencia con los años, desarrolla una escritura que va desde el lenguaje lárico más tradicional, como podemos leer en Tres canciones (1991), hasta libros ligados a la neovanguardia, como es el caso de Aguas servidas (1981), en el cual propone una escritura de características objetivas, donde el uso de un lenguaje técnico-científico marcó un punto de inflexión en la tradición poética de Chile. Por su parte, la poesía de Andrés Anwandter se encuentra ligada a una experimentación con la materialidad del poema.

3 Es interesante constatar que, a pesar de que las nuevas tecnologías provocan una sensación de progreso, también están acompañadas de un carácter mágico. En plataformas como Youtube o Facebook se comparten narraciones, videos y fotografías de fenómenos paranormales o sin explicación. Algo similar sucedió con la invención de la fotografía y el cine. A nuestro caso, el libro Fantasmas Artificiales (2015) de Valeria de los Ríos puede orientar la relación entre estos fenómenos y la escritura poética a partir de la obra de Enrique Lihn. 
Desde su primer libro El árbol del lenguaje en otoño, editado en formato dossier - cuyas hojas sueltas centran la atención de nuestra lectura-pasando por los poemas concretos de Square Poems (2002), hasta la relevancia en la sonoridad del verso, como sugiere en Banda sonora (2006), podemos observar un trabajo donde la materialidad (visual, física o sonora) son centrales para el desarrollo de una poética.

Como veremos a continuación, la importancia de los materiales en la poética de estos autores nos permite desarrollar nuevas formas de pensar lo tecnológico a partir de una lectura construida siempre en el ahora, donde el lector se vuelve el gestor de una reinterpretación constante del poema.

\section{El margen de la propia vida: antología en presente}

El margen de la propia vida reúne los poemarios Espacios de líquido en tierra (1991) y A veces cubierto por las aguas (2003), además de "Seis bestias" - publicado originalmente en www.lanzallamas.com-, el texto inédito "La casa devastada" y "Arte poética" de 25 años de poesía chilena (1999). El libro también cuenta con "Mi época es el ahora", apéndice crítico que reúne varios fragmentos de entrevista realizadas entre los años 1984 y 2013 y un prólogo escrito por Ricardo Espinaza.

La reaparición de los textos de Cociña en el panorama editorial por medio de este libro, nos permite volver a leer una obra poética que, como indica Espinaza en el prólogo de la antología, "se ha encontrado siempre en un grado de desconocimiento generalizado y al margen del canon poético nacional" (11). Más que un ajusticiamiento a su obra o la posibilidad de ingresar a ese canon, el gesto editorial de volver a publicar textos de baja distribución permite pensar en la importancia que tienen estos poemas en nuestro presente, bajo las condiciones actuales de la tecnología, tema recurrente en la poética del poeta penquista.

Esta baja distribución parece ser el origen de una "nula presencia de reseñas y de comentarios ensayísticos y en una casi total inexistencia de monografías críticas" (11). Sin embargo, la obra de Cociña ha encontrado su espacio en lectores que han sabido apropiarse de un modo de entender lo poético desde el sentido benjaminiano de un receptor distraído, que utiliza los fragmentos de su época para decir, como sugiere el novelista Alejandro Zambra (párr. 2). 
Desde una perspectiva crítica, la poesía de Cociña se sitúa en la denominada neovanguardia. Este concepto, ampliamente utilizado para caracterizar la poesía escrita durante el período de dictadura chilena, reúne una multiplicidad de artistas, poetas y performistas.

Para el crítico Oscar Galindo, el contexto político en Latinoamérica durante los años 70 va gestando mutaciones y migraciones genéricas en textos heterogéneos que se caracterizan por incorporar "no solo los discursos que provienen de otras disciplinas artísticas, sino también de otras disciplinas y saberes, hibridándose e injertándose en un macrotexto complejo de múltiples referencias culturales desjerarquizadas" (“Neovanguardias..." 79). En esta línea Cociña ha elaborado un trabajo que ha pasado del larismo a un lenguaje ligado al mundo científico y tecnológico, donde la apropiación de citas de otros campos del saber desplaza la idea de la creación original y diluyen la distancia entre autor y lector. En palabras de la crítica literaria Carolina Gainza, Cociña es un hacker de la escritura y "nosotros, los lectores, también somos llamados a serlo" ("Hackear la cultura..." párr.8).

Si bien hasta el momento hemos situado la obra de Carlos Cociña en la neovanguardia chilena, también es necesario entender su trabajo como parte de lo que Felipe Cussen llama "poesía experimental", sobre todo para evitar una lectura que reduzca su obra a una categoría temporal. El mismo Cociña sospecha al decir "para mí ha sido raro cuando me dicen en 'tú época pasaba tal cosa”" (Al margen de... 17) agregando que su época es el ahora "es esta y va a ser hasta que me muera" (17). Este gesto se corresponde con una poesía que, desde su experimentación, se actualiza con los años en la búsqueda por ampliar las posibilidades que le entregan los materiales con los cuales ha trabajado.

Para Cussen (2010), las obras experimentales están marcadas por el trabajo colectivo y colaborativo, de acá el uso constante de la cita en Cociña y la participación activa del lector, que menciona Gainza. Pero sobre todo, consideramos la marca de lo experimental desde la perspectiva de Cussen, quien señala que esta categoría no busca "llamar la atención sobre sus momentos de inspiración" ("Poesía experimental..." 23), por el contrario, pone su énfasis en "los procedimientos técnicos y materiales, incluso por encima de sus resultados y de su contenido semántico" (23). 
Al considerar una perspectiva desde la experimentación de los procedimientos técnicos y materiales, más que en el progreso temporal o su ubicación en tal o cual generación, la escritura de Cociña representaría una propuesta desencantada en torno al avance tecnológico y las plataformas virtuales, marcada por la relación material con los nuevos medios. Para el poeta, las nuevas tecnologías son materiales de trabajo y no novedades, son el resultado de una constante experimentación en el presente.

Tanto el uso de dispositivos como una página web o el lenguaje propio de la técnica científica están en el ahora del poema, se sitúan en el presente a través del lector que es llamado a actualizar a través de la lectura. Es un refresh continuo posibilitado por los métodos utilizados, por ejemplo, en el motor de búsqueda aleatorio de $A$ veces cubierto... o el uso de citas en esta obra que van desde los ensayos de neurología hasta la poética de Homero.

Esta lectura situada en el aquí y ahora no permite una posibilidad por mejorar las condiciones en un más allá, la alegría por venir no existe en esta obra, lo que sucede es lo incierto, la fragmentación de cualquier proyecto social ${ }^{4}$ para reencontrarnos en el presente y dotarlo de sentido "Todo esto es una posibilidad" ( A veces cubierto... s/p) dice uno de los poemas. Esta posibilidad existe en el ahora de la lectura.

El trabajo poético de Carlos Cociña abre paso a la incertidumbre de las posibilidades: lo que puede o no suceder. El pasado es repensado en tanto lugar que vuelve continuamente como un oleaje. Desde ese pasado nos llegan estas referencias, estos otros textos, comparables con la visión de las estrellas desde nuestro planeta, cuya luminosidad llega desde miles de años luz, fenómeno mencionado por el poeta: "La Cruz del Sur actúa como referencia, aunque sabemos que lo que vislumbrado es pasado" (A veces cubierto... s/p).

En "Arte poética", Cociña dirá que el tiempo es "relativo, pero al unísono en la materialidad del cuerpo que se puede expandir y contraer

$4 \quad \mathrm{Al}$ respecto, Jean-Louis Déotte afirma que "el arte de esta época no sería el de la ruina, que es siempre un fragmento, sino el de la ceniza a la cual el crítico difícilmente puede aferrarse. Uno no se imagina que este arte genere el estar-juntos, la comunidad, sino al contrario se esfuerza por desunir la menor conexión social, por deshacer el más elemental conceso" (8). 
sin más margen que la propia vida" (Al margen de... 7). Efectivamente, se contraen las señales que ha dejado el presente y se reescriben en la poética del autor cuando aparecen mezcladas las imágenes de un tiempo arcaico junto con otras que representan medios actuales de la técnica. Visitamos los orígenes, como señala al decir "Siempre vuelves al primer valle" (A veces cubierto... s/p) , $^{5}$ pero este retorno es a través de toda la contaminación propia de nuestra era como la ingeniería, las plataformas virtuales o el lenguaje científico. No se puede revisitar el pasado sin sentir los efectos que los nuevos medios de (re)producción han tenido en nuestra manera de percibir la realidad.

Pero, a pesar de los avances tecnológicos, volvemos, retornamos al origen. Cociña sugiere un desarraigo en ese regreso al decir que la "llamada tierra firme es una isla a la deriva" ( $A$ veces cubierto... $\mathrm{s} / \mathrm{p}$ ) y aquello que se recupera en esos retornos es "la posibilidad de establecerse en una nueva inestabilidad" (s/p). Esas islas inestables son estos textos que apenas pueden ser detenidos por un instante, contenidos en un sobre o desplegados en la superficie de una pantalla. Esa inestabilidad también se expresa en la reedición de los textos de $A$ veces cubierto..., creados en relación a una poética tecnológica y luego dispuestas en papel.

La empresa de esta reedición representa una dificultad a priori: la fragmentación constante de estos poemas que encuentran en la plataforma digital la posibilidad de una lectura cuyo orden siempre muta. El refresh que mencionábamos anteriormente se vuelve esquivo a una totalidad que indique un principio y un fin, como sucede con $A$ veces cubierto..., poemario que analizamos por su mutación, pues pasa del motor de búsqueda virtual a un sobre con hojas sueltas que busca representar la misma aleatoriedad en dos materiales distintos.

En el encuentro entre dos soportes (digital e impreso) se presentan nuevas lecturas de un mismo conjunto de poemas; versiones y nuevas relaciones entre el lector y los diversos materiales en los cuales son presentados los poemas. La sugerencia que proponemos desde ya es comprender que, a pesar de tratarse del mismo texto, el cambio de ma-

5 Para el historiador José Bengoa, el valle es el espacio geográfico de donde nacen las primeras ciudades chilenas, así como su modelo social, político y cultural y el imaginario nacional (Valle Central... 9). 
terialidad puede entenderse como una reescritura en tanto hay un original que se ve transformado con la aparición de la copia en un nuevo formato.

\section{Reedición de $A$ veces cubierto por las aguas: reescribir lo digital}

Solo el observador falto de pensamiento puede negar que hay correspondencia entre el mundo de la técnica moderna y el mundo arcaico de los símbolos.

WALTER BENJAMIN (94)

Carolina Gainza define la literatura digital como "aquella que ha sido creada para ser leída en un dispositivo electrónico y que pierde toda su significación y sentido si es que es llevada a otro formato, por ejemplo un libro" ("Literatura chilena..." párr. 2). Tal afirmación nos propone de inmediato una relación directa e inseparable entre lo escrito y el soporte que lo sostiene. Según la académica, A veces cubierto..., leída en la versión de www.poesiacero.cl, se ubicaría en esta categoría.

La obra de Cociña está compuesta por un conjunto de 39 poemas que introducen al lector en una lectura azarosa, explicada en la siguiente instrucción, que aparece en la portada de la plataforma virtual:

IMPORTANTE: Motor de búsqueda aleatorio en el cual el usuario accede a uno de los 39 poemas cada vez. Al desear ver otro poema, se despliega nuevamente al azar uno de los 39, pudiendo repetirse un poema visto anteriormente. Existe la opción de regresar, pero la elección de otro poema, será siempre aleatorio. (A veces cubierto... s/p)

Respecto de esta búsqueda aleatoria, Gainza menciona que $A$ veces cubierto... se construye como un hipertexto "donde el azar juega un rol central en la construcción de sentido así como en la experiencia estética del lector" ("La literatura chilena..." 239), experiencia que se desarrolla en la anulación de un principio o un fin de la lectura debido a la posibilidad constante de (re)armar el texto por parte del lector, se trata de "una de las características más llamativas de lo digital: la posibilidad de generar un texto sin fin con el potencial de una intervención material del lector en el texto, es decir, más allá del trabajo de significación" (239). 
Nuestra lectura de A veces cubierto... busca comparar y construir un diálogo entre la versión digital y la versión en papel ${ }^{6}$, editada por el también poeta Guido Arroyo en Ediciones Alquimia el año 2013. $\mathrm{Al}$ iniciar el libro, Arroyo nos explica que "con la intención de ser fiel a este dispositivo, el libro se imprimió en hojas sueltas, sin numerar, dispuestas en un sobre adjunto a la tapa trasera" (Al margen de... 9) y agrega, haciendo alusión a la dinámica generada por el motor de búsqueda original, "es fundamental que el lector a la hora de abrir el sobre, procure alterar todo orden, o más bien suprimir su noción de orden" (9). Esta versión genera una nueva lectura en torno al original, nos permite volver a pensar en la posible "pérdida de significación y sentido" (Gainza. "Literatura chilena..." 237) cuando el texto de carácter digital es sacado de su material original y puesto en otro soporte, como el papel impreso, que además representa una tecnología anterior, si lo pensamos en una perspectiva de progreso técnico.

Para realizar esta lectura de $A$ veces cubierto..., es necesario considerar que la escritura de Cociña se construye a partir de un conjunto de recortes de la cultura que (des)aparecen a través de estos poemas, olas cuyos movimientos marcan la orilla para borrar a continuación los mensajes que han dejado sobre ella. El autor pasa de un léxico técnico a imágenes cargadas de símbolos poéticos, como observamos en el siguiente poema:

Las redes de conexión y objetos de vidrio e iluminación, líderes en prevención de riesgos, no pueden evitar que bajo la atractiva modalidad del silencio, comience el ingreso de las estepas del sonido. La imagen de un pez vuela sobre el desierto. (A veces cubierto... s/p)

Las divergencias entre códigos que a primera vista parecen disímiles, provocan una desestabilización del sentido que se condice con la forma de esta obra: poemas dispersados para que, en su construcción infinita a través de la lectura, posibiliten nuevas divergencias, provo-

6 Existe una tercera versión de esta obra, en conjunto con la Orquesta de Poetas, fechada el año 2013 e incluida en el sitio web www.orquestadepoetas.cl/videosregistrodepoetas. Si bien no se analiza esta tercera versión, vuelve a ser relevante el trasvasije de estos poemas a través de diversas materialidades. Por lo demás, el trabajo de Orquesta de Poetas es de gran valor para el contexto que acá analizamos por el registro de diversos autores y autoras en grabaciones que unen la videoperformance, la lectura poética y el registro digital. 
cadas por la disposición aleatoria, lo que se logra tanto en el formato digital como en el papel, un desarraigo del sentido que leemos en el siguiente texto:

Los recorridos son distintos, pero el último tramo es el mismo. Los diversos caminos pasan ante antiguas casas que alguna vez fueron el final y otras veces, imperceptiblemente, se pierde el rumbo para retomarlo un poco más allá. Sin embargo el pasar lo hace, en general, una persona parecida que se reconoce en algunos olores. Todos los recorridos pueden ser los mismos, el tramo final distinto. (A veces cubierto... s/p)

La consonancia entre forma y contenido hacen de $A$ veces cubierto... una de las obras más significativas en el trabajo del poeta y retoma valor en el contraste de su original virtual frente a su aparición en el sobre de la edición en papel.

Como indicábamos con anterioridad, independientemente del material, ambas experiencias de lecturas de este poemario se reúnen en el azar provocado por el motor de búsqueda o sugerido por el editor en la antología Al margen de.... En esta última queda a disposición del lector seguir la instrucción (bien podría fijar un orden, enumerando las láminas, por ejemplo). En A veces cubierto... las alternativas son variadas, incluso podemos repetir un poema o no encontrarnos con uno después de varios intentos.

Esta multiplicidad de lecturas tiene su representación en la figura del agua, o específicamente en lo líquido, elemento primordial en la poética de Cociña cuyo fluir representa el devenir. Sobre esas aguas se sostiene el territorio de estos poemas a través de la imagen de islas cuyos habitantes viven en constante desarraigo: "Nuevamente perdí Ítaca" ( $A$ veces cubierto... s/p) dice un Ulises que, en vez de sentir nostalgia por esta pérdida, parece asumir un nuevo rol en este movimiento: "Otras islas vendrán a estos territorios. Las ocuparemos para alejarnos de ellas en los únicos viajes posibles. Aquellos que nunca nos alejarán del primer valle o playa donde no supimos de nada, pero siempre estuvimos ahí". (s/p). La incertidumbre de este Ulises da paso a un nuevo modo de habitar en ese fluido, en esas ciudades inundadas. Así también el lector de estos poemas pasa a tomar un nuevo rol, no busca un sentido fijo de la obra, pone en movimiento estos poemas 
para encontrar un significado que surge en el momento de su lectura, luego continuará con una nueva elección, un clic que lo llevará a otro espacio por habitar, links finitos que permiten infinitas posibilidades, como leemos en el siguiente fragmento: "el espacio isleño para el trabajo es metódico, lento y preciso. Nada tiene que ver con la rutina, sino con avanzar sin dejar nada. Acoge todo anuncio, aunque sea velado, para barrer la hoja que quedó" (s/p). Podemos entender el doble significado de esa hoja que quedó y que luego será barrida: la hoja de los árboles o la hoja donde está inscrito este poema.

Así como el lector provoca nuevas lecturas en cada encuentro con esta obra, la reedición de $A$ veces cubierto..., con la intención de ser fiel al motor de búsqueda, también provoca una actualización en la forma en que el lector se acerca a los dispositivos virtuales. La versión en papel no solo reescribe al original agregando nuevos significados, también retrae el dispositivo digital a su predecesor, el papel impreso.

El sobre situado en la última página de Almargen de... que contiene los 39 poemas de $A$ veces cubierto... presentados en hojas sueltas, sin numeración y con el consejo del editor al comienzo del libro, nos permite relacionar la aleatoriedad de los links de internet con una práctica anterior a la tecnología digital, la del adivino que interpreta el caos de la naturaleza arrojando piedras, cartas u observando el vuelo de las aves. Todo puede ser un mensaje revelador en un tiempo tan presente como incierto, como leemos en el siguiente poema: "Todo proceso espontáneo, natural e irreversible, aumenta la entropía del universo. Sin embargo, las feromonas se acercan al bómero nasal (sic), en desorden, desde la piel y como el almizcle se van a los sueños desde el hipotálamo. Es este un acto desde el azar" (A veces cubierto... s/p), un fenómeno corporal, descrito con aguda objetividad, también puede ser un mensaje, un lugar para la lectura.

Esta conexión entre dispositivos que apelan a distintas épocas (la carta, la página web) nos permite pensar en un tiempo que se condensa en estos poemas. Internet pasa a ser también una restitución de aquellos instrumentos adivinatorios a través de su compilado de imágenes enlazables, en constante fluidez de contenido, como lo son las cartas de un mazo, donde la elección de una alternativa siempre está dada por las condiciones del azar. 


\section{El árbol del lenguaje en otoño: metapoética de la apropiación}

¿Por qué las hojas ocupan el lugar de las hojas

y no el que queda entre las hojas?

ROBERTO JUARROZ (32)

Si debiésemos ubicar en una generación al poeta valdiviano Andrés Anwandter, esta tendría que ser la de los Náufragos de los años noventa que incluye a autores como Verónica Jiménez, Germán Carrasco, Alejandra del Río y Jaime Huenún, entre otros. Escriores chilenos de la última década del siglo XX que, para Javier Bello —otro Náufrago-, se reúnen bajo la incomodidad del lugar habitado a través de imágenes tales como:

la Caída, el Éxodo, la Conquista, la suerte de Caín, la peregrinación, el viaje de los argonautas en búsqueda de algún vellocino, el regreso de Odiseo, el descenso a los infiernos, los navegantes, los náufragos, hasta la visión crítica del mismo poema como el lugar en que el poeta y la propia escritura se sumergen para no regresar a ningún sitio conocido ... a condición del que se encuentra perdido es similar a la de los "náufragos" que, de sobrevivir, llegarán a un lugar distinto al amado, sea este el infierno o la muerte, ya que han sido desviados de su "camino", transformándose así los sentidos y las direcciones del viaje. (párr. 1)

El naufragio, como imagen que reúne a estos poetas que conviven con el proceso de transición democrática, aparece de hecho en uno de los versos de El árbol del lenguaje: "con la nostalgia de cosas que no he vivido/ como la vida privada de los árboles/ o de los náufragos" (s/n). Es un naufragio en la tradición de la poesía, donde los versos de otros, como restos de una totalidad desperdigada, permiten la construcción de la obra personal. En el caso de El árbol del..., estos restos dan cuenta de una dispersión que va desde la poesía griega hasta poetas contemporáneos al autor.

Desde sus características materiales, podemos inscribir el libro bajo la calidad de libro-objeto, ya que se trata de una carpeta o dossier - como indica la portada-, en cuyo interior encontramos 23 poemas sueltos, más uno que está inscrito en la solapa. En Chile, la tradición 
del libro objeto, que tiene al poeta Juan Luis Martínez como uno de los mayores representantes en Chile, está asociado sobre todo a la neovanguardia, incluyendo autores posteriores que han buscado distanciarse del formato libro en la experimentación con otros soportes ${ }^{7}$. Sin embargo, es evidente la influencia del fundamental Composición № 1 , de Marc Soporta, obra que dispone varias páginas sin encuadernar para que el lector las disponga (según señala la instrucción del autor), como una baraja de cartas. Tal como sugerimos en nuestra lectura, el gesto de Soporta es leído desde el carácter lúdico de mazo de cartas, hasta la relación de hipertextualidad como experiencia de una lectura colectiva al alero de las nuevas tecnologías.

Este primer trabajo de Anwandter no solo es relevante por el carácter de libro-objeto de su obra, también es el origen de una experimentación que irá desarrollando a través de los años. El artículo "Andrés Anwandter: la apertura continua" (2005) de Felipe Cussen permite comprender el sentido experimental de la obra del poeta. En el ensayo, Cussen describe el Árbol del lenguaje de la siguiente manera: "no es este el típico libro primerizo en el cual un poeta intenta impresionar al mundo con sus desgarros interiores, pero considero que deberíamos valorar esta impersonalidad como un signo de madurez en el autor, que ya sabe retirarse pudorosamente" (65). Esta impersonalidad se vuelve patente en una escritura hecha a partir de distintos referentes, algunos evidenciados en el título, como los poemas "De Los Emisarios", "Ahora mismo la aurora con sandalias doradas (Safo)", "It is evening. The house is evening, half disolved (Wallace Stevens)" o "Todos los gatos de la región son un ruido en el techo (Antonio Cisneros)" donde el autor utiliza una cita, seguida del autor de referencia para que el lector pueda tener una pista del texto origen.

$7 \quad$ La escritura aérea o sobre el desierto de Zurita, las fotocopias de Rodrigo Lira, las "Palabrarmas" de Cecilia Vicuña, son solo algunos de los gestos más representativo, en la literatura chilena reciente, de este intento por llevar la poesía a formatos no-tradicionales. Se trata de una tradición que a nivel nacional se retrae a autores como Vicente Huidobro o Nicanor Parra. Sin embargo, es evidente que en las últimas décadas esta búsqueda por nuevas materialidades se ha vuelto de mayor relevancia. Muestra de ello es la exposición "Poesía en expansión" (2019) del Museo Nacional de Bellas Artes, bajo la curatoría de Paula Honorato, que incluyó obras de Claudio Bertoni, Gonzalo Millán, Juan Luis Martínez, Ronald Kay, Hernán Meschi, Carmen Berenguer, etc. 
El trabajo de Anwandter sugiere una poética de la apropiación que, según Cristina Rivera Garza, en el ensayo Muertos indóciles (2013), puede "manifestarse a través del reciclaje, la copia, la recontextualización y el dialogismo inter o transtextual” (80). La misma autora señala que estas poéticas se multiplican cuando la escritura entra en contacto con la tecnología digital que, debido a sus procedimientos, se construye desde las relaciones dialógicas, donde la figura del genio creador se ve desplazada por la colectividad.

Lo colectivo, en los poemas de El árbol del lenguaje es la tradición literaria que se reúne en estos poemas a través de la cita, la intervención de texto o la copia. En la reescritura el poeta enfatiza en la condición polifónica de la literatura.

Así como Cociña materializa lo digital, Anwandter materializa el lenguaje. Dejando de lado el asombro de la creación original, propone, a través de la reescritura un libro que señala las dificultades de la poesía y la imposibilidad por crear un poema completamente nuevo, cuestión que retorna en la temática de su obra.

En la reescritura de Anwandter, los textos de origen son presentados al lector de forma evidente, el autor busca dejar en claro que sus poemas provienen de otros porque ese gesto es el que constituye la poética del autor, son esas "cosas que no ha vivido", las experiencias ajenas, su material de escritura.

Al igual que Cociña, Anwandter utiliza la reescritura como una forma de habitar el ahora. La tradición existe en tanto afecta el presente, como diría Garza "quien reescribe, actualiza. El motor del reescritor no es la nostalgia por el pasado, sino la emergencia del presente" (95).

Podemos considerar que en El árbol del lenguaje existe una metapoética de la apropiación, en tanto busca en estas referencias una forma de entender la poesía, sobre todo desde las dificultades que se presentan al autor para escribir su obra personal, como es representado, irónicamente, en los siguientes versos:

-el título del texto es ya un candado, su escritura ociosa, mejor decir por qué no escribir de una vez por todas
a) un poema en serio
b) un buen soneto $(\mathrm{s} / \mathrm{p})$ 
El autor duda de sus propias posibilidades como poeta, pero sobre todo duda de las posibilidades que le entrega el lenguaje para decir, a lo que solo queda aferrarse, como un náufrago, a esos restos que han dejado otros autores, aunque no logren darle una salida, pues siguen siendo candados para el escritor. En palabras de Cussen "este autor ha sabido convencernos de que vale la pena seguir sus pasos borrados, que aunque parecen devolvernos siempre al lugar inicial siempre igualmente nos burlan" ("Andrés Anwandter: la apertura..." 66). Tal como sucede en A veces cubierto..., el deseo por retornar al lugar de origen sugiere una búsqueda incesante por construir un camino de regreso.

El lenguaje nos invita a retornar pero se burla de nuestro deseo. Nos queda participar de ese juego. La misma invitación es sugerida al lector, es él quien pone en movimiento esta dinámica: "el juego concertado de tus párpados/ le da ritmo al transcurso de estos versos" ( $E l$ árbol del... s/p). Jugamos como niños que saben que las pistas que han dejado para volver a casa se perderán a medida que vayamos avanzando "en esto te alcanza la noche/ ahora no sabrás cómo volver" (s/p) dice el autor, en un verso que nos hace regresar a Cociña en esas islas que avanzan sin dejar nada, como si el verdadero valor del viaje/lectura fuese la pérdida y no la posibilidad de comprender el "verdadero sentido" de un poema.

En las dos obras que analizamos en este trabajo, la reescritura se vuelve evidente, pero no así sus referentes, difuminados entre la escritura del propio autor y aquellos materiales recuperados de otros, lo que provoca una despersonalización. Aparición y desaparición del autor cuya labor carece de importancia como señala Anwandter en uno de los poemas sin título "Condenado a un oficio menor, como barrer / los pasillos que abandonan las palabras" (s/p) su tarea es la de ir limpiando aquello que dejan las palabras, no es una actitud creadora, sino la de ir reordenando los elementos de la tradición, los restos del naufragio de la poesía.

En este sentido, lo particular de las obras que analizamos está en la posibilidad que le otorgan al lector por participar de ese constante reordenamiento. El refresh posibilitado por el motor de búsqueda de Al margen de... también está presente en el libro de Anwandter que, al estar compuesto de hojas sueltas y sin numeración, permite volver a la obra con una lectura siempre nueva, siempre otra para el lector. 


\section{Hojas sueltas: diálogo entre $A$ veces cubierto por las aguas y El árbol del lenguaje en otoño}

the material

the material

the material

JIM ANDREWS (s/R)

Lila Pagola propone que hay prácticas artísticas mediadas por los aparatos tecnológicos que ya no se pueden pensar desde la idea tradicional del artista, entre ellas está "la cooperación de los interactores convocados por obras interactivas para actualizarlas efectivamente" (10). Muchos artistas se involucran con estos medios específicamente por el potencial que tienen para generar espacios interactivos donde el lector/espectador pueda también participar e incluso hacer que su participación sea necesaria para la producción de sentido. Aveces cubierto... responde a esta interacción a través de una plataforma virtual, sin embargo, como hemos planteado, este fenómeno no es propio de un arte tecnológico. Como leemos en El árbol del... o en la versión impresa de $A$ veces cubierto.... Las poéticas tecnológicas permiten poner un mayor énfasis en la inseparable relación entre el poema y el lector.

Al reconocer el parecido entre El árbol del... y A veces cubierto..., hacemos patente la similitud entre el formato de hojas sueltas y el motor de búsqueda: una relación de azar entre el poema y el lector, siendo este último quien propone nuevas y azarosas formas de construir la obra. En palabras de Pellegrini, al referirse al texto de Anwandter, en esta aleatoriedad "el lector posee una libertad casi absoluta de copresencia autorial: al leer somos, además, creadores de nuestra propia forma de sentido" (92), un juego al que estamos invitados a través de nuestra lectura.

Podemos suponer que la similitud entre $A$ veces cubierto..., en la versión impresa en hojas sueltas con El árbol del... es casual, sin embargo nos permite constatar que este sistema no es original del medio digital. La apropiación poética de este medio permite reescribir un proceso anterior, traducir lo que el papel ya lograba producir: el azar y la interacción con un otro. Por otro lado, hay un diálogo en la reescritura que ambos autores utilizan, Cociña con el lenguaje técnico-cien- 
tífico y Anwandter con la tradición de la poesía occidental. Además, hemos evidenciado algunos cruces en las imágenes utilizadas como sucede con la referencia a las hojas, sugeridas en estas líneas de Cociña "Sentado al lado dijo que el día de ayer llovieron todas las hojas del otoño" (A veces cubierto... $\mathrm{s} / \mathrm{p}$ ) o al decir "Acoge todo anuncio, aunque sea velado, para barrer la hoja que quedó" (s/p).

También es relevante la importancia del otoño en ambas obras, como sucede con el título Árbol del... tan cercano a los siguientes versos de A veces cubierto...: "Consta tu nombre, Constanza, en estas hojas/ que el heraldo del otoño ahora respeta/ soplando tibiamente entre nosotros" (s/p). La estación donde las hojas muestran su fragilidad pero también su posibilidad de desplazarse, arrastradas por el viento, más allá de su lugar de origen.

Finalmente, el diálogo entre ambas obras nos demuestra que lo digital, en su traducción al papel, señalan el arcaísmo que hay detrás del sistema de links de internet: la selección de un objeto entre muchos para su posterior interpretación simbólica, tanto de los resultados de la búsqueda, como de la acción misma.

En estos autores, la relación entre poesía y nuevas tecnologías no es símil de una búsqueda por la novedad sino la posibilidad de mostrar (e incluir) al lector la manera en que el lenguaje se nos exterioriza a través de estos medios. En este caso, la poesía se nos presenta desde la interacción, donde el lector pone en movimiento la obra en una forma infinita de nuevos recorridos ${ }^{8}$.

\section{Conclusión: conexión otoñal/digital}

En los poemarios que analizamos, la materialidad en la cual está inscrito el poema se vuelve de vital importancia, considerándose el cambio de un soporte a otro, como un gesto de reescritura. En el caso de Cociña y las dos versiones de $A$ veces cubierto... nos refieren a dos materialidades que provocan distintas lecturas de un mismo texto. En la

8 Debemos tener en cuenta que estas infinitas posibilidades de lecturas funcionan bajo un marco de acción, son limitados los poemas/tarjetas que nos entregan los autores, así como limitadas son sus referencias, esta limitación de las referencias a las cuales podemos acceder es trabajada por Carlos Cociña de manera más evidente en el poemario Plagio del afecto (2010). 
versión digital el azar de la lectura es provocado por el motor de búsqueda que el lector utiliza para recorrer el libro; en el segundo caso, el lector puede reinterpretar la versión digital a través del soporte en papel, relacionando el clic con el gesto de la baraja de estos poemas inscritos en cartas sin numeración.

En el caso de Andrés Anwandter la disposición de los poemas en El árbol del..., presenta una forma similar a la utilizada por la versión imprenta de $A$ veces cubierto.... Nuevamente el azar se propone como eje para la lectura de estas hojas sueltas y sin numeración que pueden ser reordenadas según la ocasión de cada nueva lectura.

La aparición de una misma obra, pero en otro formato, como sucede con A veces cubierto..., abre nuevas posibilidades no solo de leer el original, sino también las obras que le preceden. La idea de un progreso siempre hacia adelante del avance tecnológico, se ve alterada cuando medios de mayor antigüedad actualizan nuestra lectura de los soportes digitales. En esta línea y tal como menciona Octavio Paz "aunque los nuevos medios no acabaron ni acabarán con la tipografía, sí la han cambiado radicalmente" (122) agregando que "el poema abandona el libro", como sucede con estas hojas sueltas que se desprenden para desplegarse en manos del lector.

En la migración hacia nuevos medios los autores retoman el diálogo con el pasado, no hay progreso sino encuentro en el ahora, como leemos en las siguientes líneas de Cociña "el color a hojas de limonero en fruto, de las grandes cumbres nevadas, entre árboles oscuros de hojas caducas, resiente las comunicaciones de medios tecnológicamente avanzados" ( $A$ veces cubierto... s/p). En el poema, tecnología y naturaleza se afectan, provocando un cambio en la forma en que comprendemos esta relación, tal como sucede en el diálogo entre estas dos obras, donde nuestra experiencia con la tecnología se ve afectada por la aparición del pasado a través de medios como la carta, el sobre, el dossier o la hoja suelta en su fragilidad como símil de la página de navegación de internet. Como dice Anwandter en uno de sus versos "la página entera es una heredad" (El árbol del... s/p), señalando que este territorio, en el medio digital o en otro, nos pertenece, en él "se recoge la imagen del otro" (s/p). 
En nuestra urgencia por resignificar el espacio digital, cuyo marco de acción ${ }^{9}$ está ligado a un sinfín de métodos mercantilizados, privativos y de vigilancia, es que volvemos a revisar estas hojas sueltas, cuya poesía nos permite abrir nuevos significados debido a sus procesos de reescritura material o temática.

La invitación de Paz, en “La nueva analogía..., de imaginar una nueva civilización es necesariamente la de un cambio en nuestra manera de comprender el espacio/tiempo en el cual nos situamos, para ello el autor mexicano imagina un mundo en el cual "se celebren la conjunción vida/muerte no como dos principios enemigos sino como una sola realidad" (125). La red de nuevas conexiones en los trabajos de estos dos autores también deviene en esa posibilidad, el árbol del lenguaje deja morir sus hojas y las suelta, son ellas las que se transformarán en los nutrientes que permitirán el nacimiento de nuevos frutos, es un ciclo natural. No hay progreso en los fenómenos de la naturaleza, hay presente, siempre el ser y la muerte, siempre el desplazamiento.

\section{Referencias bibliográficas}

Andrews, Jim. “The Material”. Vispo, 1996. Recuperado de https://web. archive.org/web/19970807090648/http://www.geocities. com/SoHo/6115/jimal.html

Arroyo, Guido. "Notas del editor". Cociña, Carlos. Al margen de la propia vida. Santiago de Chile, Editorial Alquimia, 2013, p. 9. Impreso.

Bello, Javier. "Los náufragos". Universidad de Chile, 1998. Recuperado de https://www.uchile.cl/cultura/poetasjovenes/framenaufragos.htm

Bengoa, José. Valle Central. Memorias, patrimonio y terremoto en haciendas y pueblos de Chile Central. Santiago de Chile, Catalonia, 2012. Impreso.

9 Tal como sucede en los poemarios revisados, internet nos ofrece infinitas posibilidades de conexión entre un link y otro, pero bajo un marco de acción, mientras los autores utilizan una cantidad finita de poemas y referentes, internet cuenta con su propia cantidad de información disponible, editada y manipulada. Aunque a primera vista sugiere ser el resultado de un espíritu enciclopédico, la universalidad de la información a través de internet es tan limitada como lo son la cantidad de cartas que caben en un sobre y también responden a la selección y el algoritmo utilizado por sus editores. 
Cociña, Carlos. “A veces cubierto por las aguas". Poesíacero, 2003. Recuperado de http://www.poesiacero.cl/aveces.html . Al margen de la propia vida. Santiago de Chile, Ediciones Alquimia, 2013. Impreso.

Cussen, Felipe. "Andrés Anwandter: la apertura continua". Estudios filológicos, no. 40, 2005, pp. 65-78.

"Poesía experimental: algunas propuestas críticas". Letras, 2010. Recuperado de http://www.letras.mysite.com/fc201210. html

Déotte, Jean-Loise. La época de los aparatos. Buenos Aires, Adriana Hidalgo editora, 2013. Impreso.

Benjamin, Walter. La dialéctica en suspenso: fragmentos sobre la historia. Santiago de Chile, Lom ediciones, 2014. Impreso.

Espinaza, Ricardo. "La poesía como una profundidad transparente". Cociña, Carlos. Almargen de la propia vida. Santiago de Chile, Alquimia, 2013, pp. 11-15.

Gainza, Carolina. "Hackear la cultura: poéticas del plagio en la poesía de Carlos Cociña". Centro de Cultura Digital, 2015. Recuperado de https://editorial.centroculturadigital.mx/articulo/ hackear-la-cultura-poeticas-del-plagio-en-la-poesia-decarlos-cocina

"Literatura chilena en digital: mapas, estéticas y conceptualizaciones" Revista Chilena de Literatura, no. 94, 2016, pp. 233-256.

Galindo, Oscar. "Neovanguardias en la poesía del cono sur: los 70 y sus alrededores". Estudios filológicos, no. 44, 2009, pp. 67-80.

Garza, Cristina Rivera. Los muertos indóciles. Necroescrituras y desapropiación. Colonia Chapultepec Morales, Tusquets editores, 2013. Impreso.

Juarroz, Juan. Poesía vertical: antología esencial. Buenos Aires, 2001. Impreso.

Kozak, Claudia. "Construcción y exploración de lenguajes. Del poema proceso a la tecnopoesía". Exploratorio argentino $\mathrm{Lu}$ dión, 2011. Recuperado de http://ludion.org/articulos. php?articulo_id=27

Pagola, Lila. Tensiones en la noción de autoría en los procesos de producción artística con tecnología. Buenos Aires, Exploratorio Ludión, 2011. E-book. 
Paz, Octavio. "La nueva analogía: poesía y tecnología". La casa de la presencia: poesía e historia. México, D. F., Fondo de Cultura Económica, 2014, pp. 119-126. Impreso.

Pellegrini, Marcelo. Confróntese con la sospecha. Santiago de Chile, Universitaria, 2006. Impreso.

"¿Qué es la literatura digital? Académica UDP lleva 10 años estudiando el fenómeno". Comunicación y letras, 2017. Recuperado de http://comunicacionyletras.udp.cl/que-es-la-literaturadigital-academica-udp-lleva-casi-10-anos-estudiando-elfenomeno/

Zambra, Alejandro. "Los ruidos de la imagen". Letras S5, 2008. Recuperado de http://letras.mysite.com/az261008.html 